\title{
Comparison of Outcome in Male and Female Indian Patients Undergoing Cabg, Activity Levels and Quality of Life: One Year Follow-Up Study
}

\author{
Rakesh Kumar ${ }^{1}$, Milind Padmakar Hote ${ }^{1}$, Gautam Sharma ${ }^{2}$, Bhaskar Thakur ${ }^{3}$, Balram Airan ${ }^{1}$ \\ ${ }^{1}$ Department of CTVS, Affiliation-All India Institute of Medical Sciences, New Delhi, India \\ ${ }^{2}$ Department of Cardiology, Affiliation-All India Institute of Medical Sciences, New Delhi, India \\ ${ }^{3}$ Department of Biostatistics, Affiliation-All India Institute of Medical Sciences, New Delhi, India
}

Email address:

drrakeshc0@gmail.com (R. Kumar),mphaiims@gmail.com (M. P. Hote),drsharmagautam@gmail.com (G. Sharma), bhaskarstatistics@gmail.com (B. Thakur), airanbalram@gmail.com (B. Airan)

\section{To cite this article:}

Rakesh Kumar, Milind Padmakar Hote, Gautam Sharma, Bhaskar Thakur, Balram Airan. Comparison of Outcome in Male and Female Indian Patients Undergoing Cabg, Activity Levels and Quality of Life: One Year Follow-Up Study. International Journal of Cardiovascular and Thoracic Surgery. Vol. 3, No. 5, 2017, pp. 57-62. doi: 10.11648/j.ijcts.20170305.14

Received: February 16, 2017; Accepted: March 23, 2017; Published: October 24, 2017

\begin{abstract}
This study intended to find out the outcome (in terms of quality of life and activity levels) of coronary artery bypass graft surgery $(\mathrm{CABG})$ in Indian population; and whether there are differences associated with gender of the patient. Standard SF 36 questionnaire was utilized to access patient's general health, emotional status, and social activity following surgery. It has been noted that, there is significant apprehension amongst Indian population related to open heart surgery and that patients are hesitant to return back to their normal preoperative routine following heart surgery especially CABG. The socioeconomic and educational background of the Indian patient population is commonly such that it precludes them from returning to full activity status following surgery. Hence this study is conceptualized to objectivise the outcome following CABG surgery in Indian patients and also assess any gender differences noted in the outcome following this surgery. Material and Methods: Prospective analysis was done at one year follow up of patients undergoing coronary artery bypass grafting between $1^{\text {st }}$ July $2015-31^{\text {st }}$ October 2016, without having other cardiac complications like mitral regurgitation, ventricular dysfunction, ventricular aneurysm/rupture or other complications. Patients who were operated on pump/off pump, having preop diabetes or hypertension at AIIMS New Delhi, coming for follow up at routine intervals, were included in this study. Using SF 36 questionnaire here we recorded the patients' detailed activity levels and quality of life in post-operative period, also we correlated the impact of CABG surgery with gender of patients. We compared the outcome in 168 male and female patients, who underwent CABG surgery during the study period. Follow-up was completed at intervals of 1 week, 1 month, 3 months, 6 months and 12 months following surgery. This follow-up was done both telephonically and during their office visits. Results: After 4 weeks following CABG (average 30 days), both men and women had less anxiety and symptoms related to depression than before surgery. After 6 months (average 184 days), both men and women improved in their physical and social functioning. Although changes in scale scores were similar for men and women at each time point, women scored lower than men on these domains, and had more symptoms related to depression through 1 year after CABG. Conclusions: Both male and female patients improve in physical, social, and emotional functioning after CABG, and recovery over time is similar in men and women. However women's health-related quality-of-life scale scores remained less favourable than men's through 1 year after surgery.
\end{abstract}

Keywords: Coronary Artery Disease (CAD), Coronary Artery Bypass Grafting (CABG), Internal Thoracic Artery (ITA), Left Anterior Descending Artery (LAD), Cardiopulmonary Bypass (CPB), Outer Patient Department (OPD), Analysis of Variance (ANOVA) 


\section{Introduction}

Coronary artery disease (CAD) is narrowing of the coronary arteries caused by thickening and loss of elasticity of their walls (arteriosclerosis) which when sufficiently severe, limits blood flow to the myocardium. Initially, the disease limits only coronary flow reserve (increase in flow that normally accompanies increased myocardial oxygen demands), but when sufficiently advanced, CAD reduces blood flow through the affected artery even at rest. In its most severe form, atherosclerotic CAD occludes the coronary artery.

In 1951 in Montreal, Vineberg and Miller reported direct implantation of an internal thoracic artery (ITA), also known as the internal mammary artery (IMA), into the myocardium. In 1954, Murray and colleagues were considering a direct surgical approach to CAD and reported experimental studies of anastomosing the ITA to a coronary artery. Shortly thereafter, Longmire and colleagues at the University of California in Los Angeles reported a series of patients in whom direct-vision coronary endarterectomy was performed without cardiopulmonary bypass (CPB). Subsequently, CPB was used to facilitate the operation, and Senning reported patch grafting of a stenotic coronary artery in 1961. At about this time, Effler and colleagues at the Cleveland Clinic began their pioneering efforts to achieve myocardial revascularization by a direct surgical attack on stenotic coronary lesions, as demonstrated by Sones using coronary angiography.

Largely overlooked is the first operation for CAD by Kolesov in Leningrad in 1964, in which the ITA was anastomosed to the left anterior descending coronary artery (LAD). Probably without knowledge of this contribution, in May 1967, Favaloro and Effler at the Cleveland Clinic began performing reversed saphenous vein bypass grafting. In Milwaukee in 1971, Flemma, Johnson, and Lepley described the technique and advantages of sequential grafting, in which one vein was used for several distal anastomosis.

In this study our aim was to compare the outcome of CABG in female vs male patients suffering from CAD without other major co-morbidities, and compare quality of life and physical activity status after CABG [1]. For this purpose, we used the standard SF 36 questionnaire which relates to activity and physical quality of life. We also tried to address the following questions in our study on Indian patients [21].

Whether myocardial dysfunction preoperatively interferes with the prognosis in postoperative period [2]; the association of other co-morbidities like diabetes, hypertension with CAD [3-4]; how age at the time of surgery affects the outcome; how quality of life and activity changes after surgery [5-8]. We have analysed the data from the answered questionnaires after one year of patients' follow up after CABG surgery.

The health related quality of life, life satisfaction, and cardiac related symptoms of 168 men and women who underwent $\mathrm{CABG}$ surgery are described up to first annual follow up after CABG surgery, using data from the post CABG behavioural study.

\section{Aims \& Objective}

It has been noted that, there is significant apprehension amongst Indian population related to open heart surgery and that patients are hesitant to return back to their normal preoperative routine following heart surgery especially CABG. The socioeconomic and educational background of the Indian patient population is commonly such that it precludes them from returning to full activity status following surgery.

Hence this study was conceptualized to assess the outcome following $\mathrm{CABG}$ surgery in Indian patients and also to assess any gender differences noted in the outcome following this surgery. The outcome from the study may provide a basis for recommendation of stronger educational and rehabilitative measures to patients undergoing this major surgery, so that they may return to a more complete level of healthy lifestyle. There has been growing interest in measures of health related quality of life outcomes of CABG surgery and other cardiovascular therapies.

\section{Patients and Methods}

This study includes patients who underwent prospective follow up at AIIMS New Delhi, for one year after coronary artery bypass grafting. They did not have other coronary artery disease complications like mitral regurgitation, ventricular dysfunction, and ventricular aneurysm/rupture. These patients were operated on pump/off pump and had preop risk factors like diabetes or hypertension. Using SF 36 questionnaire, we recorded and compared patient's detailed activity levels and quality of life in pre and post-operative period [9-10]. We specially observed the impact of gender on quality of life following CABG surgery. Follow up interval was 1 week, 1 month, 3 months, 6 months and 12 months. All patients fulfilling inclusion criteria, during the period of study were included. Follow-up was done either telephonically or during their outer patient department (OPD) visits. Prospective data collection was done after ethical clearance by the institute ethical committee (Ref. No IESC/T-369/22.07.2015, RT-17/26.08.2016). Patients preoperative characteristics, echocardiography findings, coronary angiography finding, intra operative details, endarterectomy details, no of grafts placed, graft details, post operative course were tabulated. Follow-up up to one year was analysed in male and female Indian patients. The details of the parameters studied are given in the SF 36 questionnaire (appendix 1). Data was presented as odds ratio (OR) or mean $\pm \mathrm{SD} /$ median (range) as appropriate. The data obtained was subjected to detailed univariate and multivariate analysis to identify significant factors affecting the outcomes during and after surgery. 


\subsection{Inclusion Criteria}

a) Patients undergoing isolated $\mathrm{CABG}$ operation for coronary artery disease (CAD) between $1^{\text {st }}$ July 2015 and $31^{\text {st }}$ October 2016 were included.

b) Normal biventricular function. (LVEF $>50 \%$ ).

\subsection{Exclusion Criteria}

c) Age $>70$ years.

d) Patients with other complications of ischemic heart disease like ischemic mitral regurgitation/ concomitant valve disease.

e) Patient with ventricular dysfunction. (LVEF $<50 \%$ ).

f) Patient with other co-morbid conditions, except diabetes and hypertension.

\subsection{Data Collection}

Socio-demographic data was recorded in interviews and on an SF 36 questionnaire at baseline and follow-up visits. Physical functioning measures included the general health, physical health (walking indoors, moving in and out of bed or chair, and self care: eating, dressing, or bathing, house work, walking outdoors, walking stairs, shopping, transportation, moderate exercise), energy and emotional health, pain, social functioning (visiting friends or relatives, participating in com-munity activities, taking care of family) was measured with the use of a subscale of the Functional Status (SF) Questionnaire.

\subsection{Statistical Methods}

Proportions were compared by means of $\mathrm{Chi}^{2}$ tests or events and proportions in ordered categories were analyzed by means of logistic regression. Continuous data are presented as mean (SD) and analyzed by means of 2-sample $t$ tests, linear regression and analysis of variance. Longitudinal data were analyzed by means of generalized linear models that account for baseline and follow-up correlations. Total 168 patients meeting defined criteria, undergoing CABG at the All India Institute of Medical Sciences, New Delhi, India, were included in the study. The study protocol was duly approved by the ethics committee of the Institute and informed consent was obtained from the parents of all the patients in the study. The study was designed and the sample size was calculated to achieve a minimum statistical power of 0.9 .

Probabilities associated with test statistics ( $P$ values) are presented without correction for multiple comparisons. Because many comparisons are made in these analyses, $P$ value of 0.01 has been considered significant. Final score of postoperative quality of life and their activity levels were developed at all the baseline, 1st week, 1st month, 3rd month, 6th month and at the end of 1 year after the surgery; completed and analyzed at all the given time point and compared between male and female. Independent t-test at each time point was carried out for any significant difference between male and female. There is no variation (Standard
Deviation $=0$ ) in the overall score of quality of life and their activity levels after baseline therefore the possible repeated measures ANOVA test could not being performed. Additionally various demographic characteristics and cardiovascular risk factors and other clinical risk factors were tested through Chi-square test, independent t-test and ranksum test for any possible association with male and female.

SF 36 scoring system is made in such a way that higher score is given for poor general health, poor functional status, maximum limitation of activity, maximum emotional disturbances, maximum pain, poor social activity, and lack of energy. Lowest score was given to vice-versa, ranging from one to six.

\section{Results}

Patient characteristics and preoperative medical conditions are presented in Table 1.

Preoperative data were acquired from the majority of 168 patients $(87.5 \%$ of men and $12.5 \%$ of women). Preoperative characteristics and medical conditions were compared. Women undergoing $\mathrm{CABG}$ were older and there were more incidence of diabetes in women (P.004). They were similar in other characteristics.

Health-related quality of life: We compared health-related quality of life according to age, sex. There were no sex differences in symptoms or health-related quality of life.

The percentages of men and women who had pain and shortness of breath more often than 1 day per week were similar. Women had higher scores (more depressive emotional symptoms) and lower scores on scales of basic activities of daily living, intermediate activities and social functioning than men (Table 2). After surgery, there were no important differences between men and women in the frequency of their return to work (Table 3). Men and women differed little in anxiety and life satisfaction after surgery (Table 4).

Baseline and follow-up health-related quality of life (preoperative data):

Male and female patients did not differ from each other in pattern of recovery from baseline in any health-related quality-of-life domain or in life satisfaction. Anxiety decreased and life satisfaction improved from baseline by the 3 month (on average, 90 days) follow-up visit ( $P .05$ each) (Table 5). Social activity improved relative to baseline by the 3-month (on average, 90 days) follow-up visit ( $P .05$ each) and did not change substantially thereafter (Table 6).

Basic physical function and social function scale scores had declined at the 1 week and 1 month follow-up visit but had improved by the 3-months follow-up visit.

Improvements in these domains were maintained through the last follow-up. The proportions of patients who had pain, tiredness, or shortness of breath more than once per week decreased from baseline through 3 months and remained below preoperative levels for each symptom after 1 year after surgery. Although data from all time points show little difference between men and women in pain, tiredness or 
shortness of breath, women had more shortness of breath $(P .8)$ and possibly more tiredness (P.7). Age did not influence the percentage of patients who had these cardiac symptoms, health-related quality-of-life domains or life satisfaction in recovery after surgery.

Table 1. Patients' demographic characteristics and medical conditions by sex (preoperative data).

\begin{tabular}{lll}
\hline Characteristic & Men $(\mathbf{n}=\mathbf{1 4 7})$ & Women $(\mathbf{n = 2 1})$ \\
\hline Demographics $(\%)$ & $87.5(147)$ & $12.5(21)$ \\
Age mean $(\mathrm{yrs})$ & 58.8 & 59.2 \\
Education $10^{\text {th }}(\%)$ & 64 & 61 \\
Diabetes $(\%)$ & $56(38.1)$ & $15(71.3)$ \\
Hypertension (\%) & $82(55.7)$ & $16(76.1)$ \\
Ejection fraction $(\%)$ & 58.6 & 61.3 \\
\hline
\end{tabular}

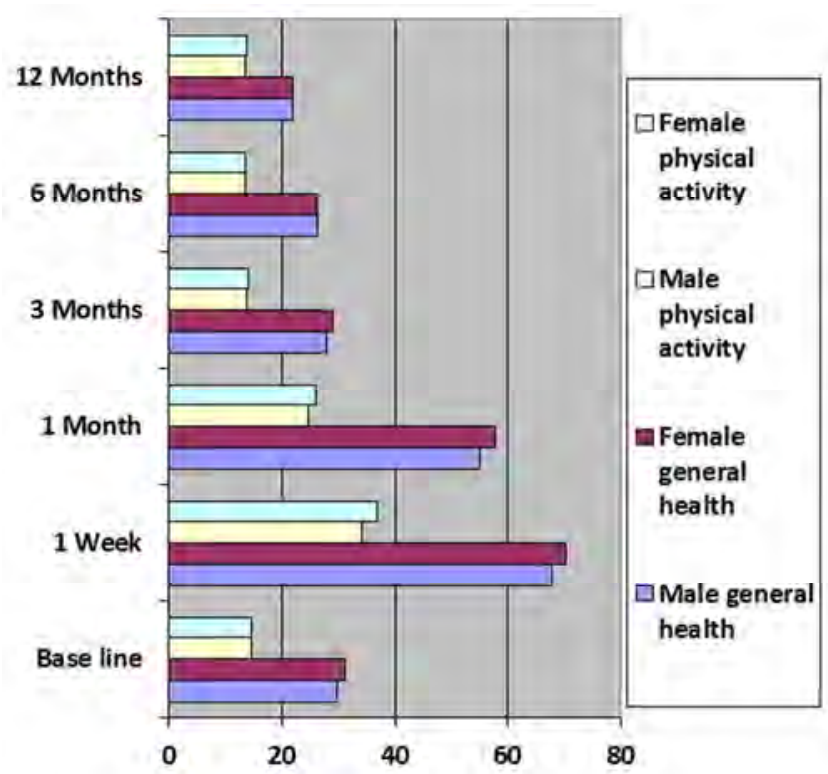

Figure 1. SF 36 score ( $X$-axis) in male and female patients' mean Base line pre-op with post-operative duration (Y-axis) in week and months.

Table 2. General health - Mean $\pm S D$ SF 36 score in male and female patients' with time since $C A B G$.

\begin{tabular}{lll}
\hline Symptoms & Male $(\mathbf{n}=\mathbf{1 4 7})$ & Female $(\mathbf{n}=\mathbf{2 1})$ \\
\hline Baseline & $29.9 \pm 0.6(\mathrm{n}=147)$ & $31.1 \pm 0.6(\mathrm{n}=21)$ \\
1 week & $67.9 \pm 0.8(\mathrm{n}=147)$ & $70.2 \pm 0.6(\mathrm{n}=21)$ \\
1 month & $55.1 \pm 0.6(\mathrm{n}=147)$ & $57.8 \pm 0.9(\mathrm{n}=21)$ \\
3 months & $27.9 \pm 0.6(\mathrm{n}=147)$ & $28.9 \pm 0.8(\mathrm{n}=21)$ \\
6 months & $26.3 \pm 0.6(\mathrm{n}=106)$ & $26.2 \pm 0.4(\mathrm{n}=13)$ \\
12 months & $21.9 \pm 0.6(\mathrm{n}=54)$ & $21.9 \pm 0.6(\mathrm{n}=5)$ \\
\hline
\end{tabular}

Table 3. Limitation of activities (return to work) - Mean \pm SD SF 36 score in male and female patients' with time since CABG.

\begin{tabular}{lll}
\hline Symptoms & Male $(\mathbf{n}=\mathbf{1 4 7})$ & Female $(\mathbf{n}=\mathbf{2 1})$ \\
\hline Baseline & $29.6 \pm 0.6(\mathrm{n}=147)$ & $29.9 \pm 0.6(\mathrm{n}=21)$ \\
1 week & $67.9 \pm 0.8(\mathrm{n}=147)$ & $68.2 \pm 0.6(\mathrm{n}=21)$ \\
1 month & $55.1 \pm 0.6(\mathrm{n}=147)$ & $57.2 \pm 0.9(\mathrm{n}=21)$ \\
3 months & $27.9 \pm 0.6(\mathrm{n}=147)$ & $28.9 \pm 0.8(\mathrm{n}=21)$ \\
6 months & $26.3 \pm 0.6(\mathrm{n}=106)$ & $26.2 \pm 0.4(\mathrm{n}=13)$ \\
12 months & $21.9 \pm 0.6(\mathrm{n}=54)$ & $21.7 \pm 0.6(\mathrm{n}=5)$ \\
\hline
\end{tabular}

Table 4. Physical health problems - Mean $\pm S D S F 36$ score in male and female patients' with time since $C A B G$.

\begin{tabular}{lll}
\hline Symptoms & Male $(\mathbf{n}=147)$ & Female $(\mathbf{n}=21)$ \\
\hline Baseline & $14.6 \pm 1.2(\mathrm{n}=147)$ & $14.5 \pm 0.9(\mathrm{n}=21)$ \\
1 week & $34.0 \pm 0.6(\mathrm{n}=147)$ & $36.9 \pm 0.2(\mathrm{n}=21)$ \\
1 month & $24.7 \pm 0.3(\mathrm{n}=147)$ & $25.9 \pm 0.6(\mathrm{n}=21)$ \\
3 months & $13.7 \pm 0.4(\mathrm{n}=147)$ & $14.1 \pm 0.2(\mathrm{n}=21)$ \\
6 months & $13.5 \pm 0.6(\mathrm{n}=106)$ & $13.6 \pm 0.7(\mathrm{n}=13)$ \\
12 months & $13.4 \pm 0.4(\mathrm{n}=54)$ & $13.7 \pm 0.6(\mathrm{n}=5)$ \\
\hline
\end{tabular}

Table 5. Emotional health problems - Mean \pm SD SF 36 score in male and female patients' with time since $C A B G$.

\begin{tabular}{lll}
\hline Symptoms & Male $(\mathbf{n}=147)$ & Female $(\mathbf{n}=21)$ \\
\hline Baseline & $14.6 \pm 1.2(\mathrm{n}=147)$ & $14.5 \pm 0.9(\mathrm{n}=21)$ \\
1 week & $36.0 \pm 0.8(\mathrm{n}=147)$ & $38.1 \pm 0.2(\mathrm{n}=21)$ \\
1 month & $24.7 \pm 0.3(\mathrm{n}=147)$ & $25.9 \pm 0.6(\mathrm{n}=21)$ \\
3 months & $14.7 \pm 0.4(\mathrm{n}=147)$ & $14.9 \pm 0.2(\mathrm{n}=21)$ \\
6 months & $13.2 \pm 0.6(\mathrm{n}=106)$ & $13.6 \pm 0.4(\mathrm{n}=13)$ \\
12 months & $13.1 \pm 0.4(\mathrm{n}=54)$ & $13.2 \pm 0.6(\mathrm{n}=5)$ \\
\hline
\end{tabular}

Table 6. Social health problems - Mean $\pm S D$ SF 36 score in male and female patients' with time since $C A B G$.

\begin{tabular}{lll}
\hline Symptoms & Male $(\mathbf{n}=147)$ & Female $(\mathbf{n}=\mathbf{2 1})$ \\
\hline Baseline & $14.6 \pm 1.2(\mathrm{n}=147)$ & $14.5 \pm 0.9(\mathrm{n}=21)$ \\
1 week & $35.0 \pm 0.6(\mathrm{n}=147)$ & $36.9 \pm 0.2(\mathrm{n}=21)$ \\
1 month & $23.7 \pm 0.3(\mathrm{n}=147)$ & $23.9 \pm 0.3(\mathrm{n}=21)$ \\
3 months & $13.3 \pm 0.5(\mathrm{n}=147)$ & $13.9 \pm 0.2(\mathrm{n}=21)$ \\
6 months & $13.2 \pm 0.6(\mathrm{n}=106)$ & $13.6 \pm 0.7(\mathrm{n}=13)$ \\
12 months & $13.2 \pm 0.4(\mathrm{n}=54)$ & $13.4 \pm 0.6(\mathrm{n}=5)$ \\
\hline
\end{tabular}

\section{Discussion}

Health related quality-of-life measures have become valuable tools for assessing the effects of CABG surgery on patients' symptoms and daily functioning. In the POST CABG behavioural study, the prospective design and adequate numbers of male and female patients provided the opportunity to describe and compare quality-of-life outcomes [11-12].

In our preoperative data, female patients who had CABG were older. Before surgery, female patients in our study had poor economic and social resources and were less well educated. They had a higher prevalence of diabetes and hypertension. Before surgery, women had less favourable physical, social, and emotional functioning scale scores than their male counterparts [28].

Their postoperative outcomes were compared with patients who completed preoperative evaluations. Health-related quality-of-life outcomes were essentially the same for these patients.

Our findings are consistent with findings of previous quality-of-life investigations of CABG patients. Cardiovascular symptoms, quality of life in terms of social, physical, and emotional function, and life satisfaction improve in the year after surgery. During an initial period after surgery, we observed some decline in physical and social function; most patients resumed normal or improved 
function 6 months to 1 year after CABG surgery [15, 20, 22]. These improvements are sustained; out-comes after 6 months are generally comparable to those observed in the year after surgery [16-17].

Men and women recover and improve in health related quality of life similarly after CABG surgery, but women have less favourable scale scores than men before and after surgery [13-14]. Changes in health related quality-of-life scale scores indicate as much benefit for women as for men, although less favourable operative outcomes have been reported for women than for men by other investigators [24-26].

Sex could make a difference in reporting symptoms of coronary artery disease, in patient selection for $\mathrm{CABG}$, in responses to questions about health-related quality of life, or in perceptions on health-related quality-of-life domains [18, 27]. The POST CABG behavioural study design did not address these potential sources of differences between men and women in health-related quality-of- life scale scores [19, 23].

In our study, the frequency of return to work of those employed before surgery was approximately $58 \%$ for men and $65 \%$ for women. In similar patient populations, rates of return to work ranged from $50 \%$ to $90 \%$ in one study, $22 \%$ of the patients less than 60 years did not return to work by 2 years after surgery for cardiac reasons. Unlike other studies, our percentages of men and women employed before surgery who returned to work were comparable; our study included many patients older than 65 years of age.

In conclusion, women in the POST CABG behavioural Study were older, had less favourable physical functioning, and reported more depressive symptoms and fewer social supports than men before surgery. After CABG, many of these differences remained. Both men and women report being in more favourable condition after CABG than before and have similar patterns of recovery in health-related quality of life. After an initial phase of convalescence, during which basic activities of daily living and social function showed a modest decline from preoperative levels, both male and female patients improved in physical, social, and emotional functioning and symptoms by 3 months to 1 year after CABG surgery and maintained their levels of recovery in the year after surgery.

Limitations of study:

Small number of female patients in the study population in comparison to male patients.

Disclosure: no conflict of interest

Ethical approval granted.

\section{Conclusion}

Four week following CABG, both men and women had less anxiety and symptoms related to pain and depression compared to before surgery. However there were slightly increased levels of limitation of activities and physical health problems in women ( 1 week, 1 month and 3 months) compared to men (but not statistically significant).

At 6 months, both men and women improved in physical and social functioning.

Although changes in scale scores were similar for men and women at each time point, women scored lower than men on these domains and had more symptoms related to depression through one year after CABG.

Patients aged less than 55 years have faster recovery and resume their work early.

Both male and female patients improve in physical, social, and emotional functioning after $\mathrm{CABG}$, and recovery over time is similar in men and women. However women's healthrelated quality-of-life scale scores remained less favourable than that of men 1 year following surgery.

\section{References}

[1] Early and long term coronary artery bypasses grafting outcomes in patients under 45 years of age. Zwoliński R, Jander S, Ostrowski S, Bartczak K, Adamek Kośmider A, Banyś A, Jaszewski R. Kardiol Pol. 2013; 71 (1): 32-9.

[2] Hovnanian AL, de Matos Soeiro A, Serrano CV, de Oliveira SA, Jatene FB, Stolf NA, et al. Surgical myocardial revascularization of patients with ischemic cardiomyopathy and severe left ventricular disfunction. Clinics 2010; 65: 3-8.

[3] Quality of life after PCI vs CABG among patients with diabetes and multivessel coronary artery disease: a randomized clinical trial Abdallah MS, Wang K, Magnuson EA, Spertus JA, JAMA. 2013 Oct 16; 310 (15): 1581-90. doi: 10.1001/jama.2013.279208.

[4] Quality of life 12 years after on-pump and off-pump coronary artery bypass grafting. Järvinen $\mathrm{O}$, Hokkanen M, Huhtala $\mathrm{H}$. Coron Artery Dis. 2013 Dec; 24 (8): 663-8. doi: 10.1097/MCA.0000000000000037.

[5] Schulz P, Zimmerman L, Barnason S, Nieveen J. Gender differences in recovery after coronary artery by pass graft surgery. Prog Cardio- vasc Nurs. 2005 Spring; 20 (2): 58-64.

[6] Vaccarino V, Lin ZQ, Kasl SV, Mattera JA, Roumanis SA, Abram- son JL, et al. Gender differences in recovery after coronary artery bypass surgery. J Am Coll Cardiol 2003; 41: 307-14.

[7] Lindquist R, Dupuis G, Terrin ML, Hoogwerf B, Czajkowski $\mathrm{S}$, Herd JA, et al. Comparsion of health-related quality-of-life out-comes of men and women after coronary artery bypass surgery through 1 year: findings from the POST CABG Biobehavioral Study. Am Heart J 2003; 146: 1038-44.

[8] Schulz P, Zimmerman L, Barnason S, Nieveen J. Gender differences in recovery after coronary artery bypass graft surgery. Prog Cardio- vasc Nurs. 2005 Spring; 20 (2): 58-64.

[9] Soto M, Failde I, Márquez S et al. Physical and mental component summaries score of the SF-36 in coronary patients. Quality of Life Research 2005; 14: 759-768.

[10] Ware JE Jr, Sherbourne CD. The MOS 36-item short-form health survey (SF-36). I. Conceptual framework and item selection. Med Care 1992; 30: 473-83.

[11] Wenger N, Mattson M, Furberg C, et al. Assessment of quality of life in clinical trials of cardiovascular therapies. Am J Cardiol 1984; 54: 908 -13? 
[12] Ayanian JZ, Guadognoli E, Cleary PD. Physical and psychosocial functioning of women and men after coronary artery bypass surgery. JAMA 1995; 274: 1767-70.

[13] Czajkowski S, Lindquist R, Hoogwerf B, et al. Women coronary artery bypass graft $(\mathrm{CABG})$ surgery patients are sicker and have fewer social and economic resources than men (Abstract). Circula-tion 1992; 86 (1 Suppl): I-674.

[14] Czajkowski S, Terrin M, Lindquist R, et al. Comparison of preoperative characteristics of men and women undergoing coronary artery bypass grafting (the Post Coronary Artery Bypass Graft [CABG] Biobehavioral Study). Am J Cardiol 1997; 79: 1017-24.

[15] The prognostic significance of declining health-related quality of life scores at 6 months after coronary artery bypass surgery Gunn JM, Lautamäki AK, Hirvonen J, Kuttila KT QJM. 2014 May; 107 (5): 369-74. doi: 10.1093/qjmed/hct256. Epub 2013 Dec 28.

[16] Quality-of-life outcomes with coronary artery bypass graft surgery in ischemic left ventricular dysfunction: a randomized trial. Mark DB, Knight JD, Velazquez EJ, etalAnn Intern Med. 2014 Sep 16; 161 (6): 392-9. doi: 10.7326/M13-1380.

[17] The long-term effect of perioperative myocardial infarction on health-related quality-of-life after coronary artery bypasses grafting. Järvinen $\mathrm{O}$, Hokkanen $\mathrm{M}$, Huhtala $\mathrm{H}$. Interact Cardiovasc Thorac Surg. 2014 May; 18 (5): 568-73. doi: 10.1093/icvts/ivt543. Epub 2014 Feb 4.

[18] Does coronary artery bypass grafting improve quality of life in elderly patients? Baig K, Harling L, Papanikitas J, Attaran S, Ashrafian H, Casula R, Athanasiou T. Interact Cardiovasc Thorac Surg. 2013 Sep; 17 (3): 542-53. doi: 10.1093/icvts/ivt220. Epub 2013 May 27. Review.

[19] Quality of life changes after coronary artery bypass graft surgery]. Zhao Z, Chen Y, Liu X, Li X, Liu G, Hu DY. Zhonghua Xin Xue Guan Bing Za Zhi. 2012 Jun; 40 (6): 4926. Chinese.

[20] Quality of life and functional capacity one year after coronary artery bypass graft surgery. Nedeljković UD, Krstić NM,
Varagić-Marković SLj, Putnik SM. Acta Chir Iugosl. 2011; 58 (3): 81-6.

[21] Sinha R, van den Heuvel WJA, Arokiasamy P. Validity and Reliability of MOS Short Form Health Survey (SF-36) for Use in India. Indian Journal of Community Medicine: Official Publication of Indian Association of Preventive \& Social Medicine. 2013; 38 (1): 22-26. doi: 10.4103/09700218.106623 .

[22] Lindquist, Ruth, et al. "Comparison of health-related qualityof-life outcomes of men and women after coronary artery bypass surgery through 1 year: findings from the POST CABG Biobehavioral Study." American heart journal 146.6 (2003): 1038-1044.

[23] Bute, Barbara Phillips, et al. "Female gender is associated with impaired quality of life 1 year after coronary artery bypass surgery." Psychosomatic medicine 65.6 (2003): 944951.

[24] Keresztes, Patricia A., et al. "The coronary artery bypass experience: gender differences." Heart \& Lung: The Journal of Acute and Critical Care 32.5 (2003): 308-319.

[25] Lindsay, Grace M., et al. "Coronary artery disease patients' perception of their health and expectations of benefit following coronary artery bypass grafting." Journal of advanced nursing 32.6 (2000): 1412-1421.

[26] Schulz, Paula, et al. "Gender differences in recovery after coronary artery bypass graft surgery." Progress in cardiovascular nursing 20.2 (2005): 58-64.

[27] Sjöland, H., et al. "Improvement in quality of life differs between women and men after coronary artery bypass surgery." Journal of internal medicine 245.5 (1999): 445-454.

[28] Krannich, J-H., et al. "Health-related quality of life two days before, ten days and one year after coronary artery bypass graft surgery." The Thoracic and cardiovascular surgeon 55.05 (2007): 288-292. 